\title{
LITERATURA E ENSINO DE GEOGRAFIA: DIÁLOGO PARA ANALISAR A DESVALORIZAÇÃO DOS RIOS NA PAISAGEM URBANA
}

\author{
Literature and geography teaching: dialogue to analyze the devaluation of rivers in the \\ urban landscape
}

Literatura y geografia: diálogo para analizar la devaluación de los ríos em el paisaje urbano

\section{Daiana Freitas Nascimento}

*UERJ-FFP-daianafreitasnascimento@hotmail.com

\author{
Recebido em 19/10/2019. Aceito para publicação em 20/10/2019. \\ Versão online publicada em 10/11/2019 (http://seer.ufrgs.br/paraonde)
}

\begin{abstract}
Resumo:
O trabalho objetiva analisar como a temática referente à desvalorização dos rios presentes na paisagem urbana pode ser desenvolvida no ensino da geografia por meio da mediação com a literatura, em particular com o gênero poético. A problematização das questões ambientais que permeiam a cidade, como é o caso da situação degradante da maioria dos rios presentes no contexto urbano, pode permitir aos discentes construírem uma análise crítica espacial sobre os lugares onde ensejam suas práticas socioespaciais cotidianas. Desse modo, a partir da análise da paisagem urbana que constitui os espaços de vivência dos alunos pode haver a construção de uma consciência espacial sobre os principais elementos socioambientais perpassados no estudo da cidade. Nesse contexto, a literatura a partir do gênero poético por abordar, entre outros aspectos, a dimensão espaço-temporal do real, assim como a Geografia, pode ser um caminho para a construção de atividades didáticas que tenham como objetivo o delineamento de uma aprendizagem significativa. A Literatura apresenta diferentes falas sobre o mundo e a partir da congruência dos aspectos objetivos e subjetivos aborda questões relacionadas à problemática urbana, como as proposições ambientais. Para a concepção metodológica, utilizou-se a abordagem qualitativa a partir da construção de oficinas pedagógicas realizadas com alunos do ensino médio de duas escolas públicas localizadas no município de São Gonçalo - RJ. Como resultado, pode-seressaltar o desenvolvimento de atividades didáticas, a partir de diferentes campos do saber, a fim de abordar os conteúdos e conceitos que permeiam a temática em discussão.
\end{abstract}

Palavras-chave: Geografia. Literatura. Ensino de Geografia. Rios urbanos. Atividades Didáticas.

\section{Resumen:}

El estudio tiene como objetivo analizar cómo el tema relativo a la devaluación de los ríos presentes en el paisaje urbano se puede desarrollar en la enseñanza de la geografía a través de la mediación con la literatura, en particular con el género poético. La problemática de las cuestiones ambientales que impregnan la ciudad, como es el caso de la situación degradante de la mayoría de los ríos presentes en el contexto urbano, puede permitir a los estudiantes construir un análisis espacial crítico en los lugares donde proporcionan sus prácticas socioespaciales. Así, a partir del análisis del paisaje urbana que constituye los espacios de experiencia de los estudiantes, puede haber la construcción de una conciencia espacial sobre los principales aspectos socioambientales permeables en el estudio de la ciudad. En este contexto, la literatura, a traves del género poético, abordando, entre otros aspectos, la dimensión espacial-temporal de lo real, así como la geografía, puede ser un camino para la construcción de actividades didácticas que tienen como objetivo el diseño de 
un aprendizaje significativo. La literatura presenta diferentes declaraciones sobre el mundo y desde la congruencia de los aspectos objetivos y subjetivos aborda cuestiones relacionadas con problemas urbanos como las propuestas ambientales. Para la concepción metodológica, utilizamos el enfoque cualitativo basado en la construcción de talleres pedagógicos realizados con estudiantes de secundaria de dos escuelas públicas ubicadas en el municipio de San Gonçalo-RJ. Como resultado, se puede destacar el desarrollo de actividades didácticas, desde diferentes campos del conocimiento, con el fin de abordar los contenidos y conceptos que impregnan el tema en discusión.

Palabras-clave:Geografía. Literatura. Enseñanza de geografía. Ríos urbanos. Actividades didácticas.

\section{Introdução}

Analisar o papel da Geografia enquanto disciplina no mundo pós-moderno não é um movimento simples. As dinâmicas socioeconômicas e ambientais estão em constante transformação e os seus reflexos se ensejam de diferentes maneiras no espaço geográfico. Assim, pensar sobre as questões dialéticas constituintes no espaço, socialmente produzido pelo homem, impõe ao ensino de geografia o delineamento de novos enfoques e novas perspectivas. Nesse contexto, a geografia escolar deve fomentar nos alunos o desenvolvimento de uma consciência espacial crítica que os permitem pensar a sua realidade enquanto sujeitos inseridos num mundo cada vez mais contraditório. Dentre as formas de expressão dos saberes humanos, encontra-se a literatura. Nesse sentido, esse artigo propõe a articulação da geografia escolar com a arte literária.

\section{Desenvolvimento}

De acordo com Cavalcanti (2012, p. 89), no atual contexto escolar as práticas de ensino de geografia devem ter como um de seus pressupostos "promover a formação geral de crianças e jovens para atuar na sociedade, buscando desenvolver nos alunos capacidade de agir de modo autônomo, de resolver problemas e tarefas cotidianas, estabelecendo as próprias metas, definindo as próprias estratégias". Desse modo, os conteúdos abordados por essa disciplina precisam estar articulados as práticas sociais dos alunos, a fim de que os saberes geográficos assumam, de fato, um significado social.

Callai (2015, p. 224) argumenta sobre a relevância dos alunos aprenderem a espacialidade dos lugares onde vivem e, para que isso ocorra, é necessário que haja o desenvolvimento de uma forma geográfica de pensar que "contribua para a formação de sujeitos, a fim de que estes realizem aprendizagens significativas, tornando a Geografia mais que mera ilustração. Isso significa a reflexão sobre como ficam os conteúdos, [...] e de como fazer o seu tratamento". Nesse contexto, a seleção dos conteúdos, bem como, o seu tratamento didático deve refletir todas essas questões, a fim de que o ensino de geografia possa efetivamente ser um caminho possível para a construção de uma leitura mais argumentada e plural do mundo pelos sujeitos que o constitui.

Desse modo, o desenvolvimento de novas metodologias para abordar os conteúdos geográficos é um movimento importante para pensar uma aula mais

ParaOnde!?, Porto Alegre, v.12 n.2, p.115-123, 2019.http://seer.ufrgs.br/paraonde Edição Especial - III Colóquio de Pesquisadores em Geografia Física Ensino de Geografia 
dinâmica, na qual os alunos também sejam sujeitos ativos na produção do conhecimento. Nesse contexto, a aproximação da geografia com a literatura aparece como uma alternativa interessante para refletir o tratamento dos fenômenos geográficos a partir de diferentes linguagens. Assim, por meio do encontro entre esses saberes, busca-se a problematização do conteúdo escolar, bem como, a valorização de outras linguagens e formas de expressão para abordar as temáticas geográficas. "Literatura e Geografia possuem linguagens próprias, formas de dizer e ver o mundo específicas, que revelam e criam outros mundos. As obras literárias são [...] selecionadas segundo a experiência, a classe, o interesse do leitor, atendendo a necessidade do momento." (MARANDOLA; OLIVEIRA, 2009, p. 502).

As obras literárias podem compartilhar com o leitor informações sobre as paisagens, os lugares, como também, o contexto socioespacial em que são projetadas as narrativas, poiselas não decorrem apenas dos processos imaginativos ou fantasiosos dos sujeitos, mas sim das múltiplas relações que esses desenvolveram ao se deparar com uma realidade próxima ou distantes de suas vidas. Sobre a utilização da literatura no contexto escolar, Alves (2015, p. 145) ressalta que a responsabilidade do professor nessa perspectiva é o de mediador da leitura eprecisa "cultivar a capacidade de ouvir o outro, de pôr em relevo sua fala, o que não significa aceitar tudo que é enunciado sobre o texto. Colocar em discussão os vários modos de apreensão da leitura que circula na peculiar comunidade de leitores que é a sala de aula."

Mediante a leitura dos poemas, pode-se construir uma representação parcial, plural, objetiva ou subjetiva de uma determinada realidade, uma vez que eles podem ser compreendidos enquanto um discurso sobre o real formado,a partir da relação que o autor estabelece com o meio histórico, cultural e social no qual está inserido. De acordo com Alves (2008, p. 28), a aproximação afetiva dos alunos, de forma gradativa e permanente com os poemas, poderá desenvolver, a partir do contexto escolar, leitores sensíveis que serão "capazes de autonomia de voo quando saírem da escola,comotambém formar cidadãos e contribuir para a nossa missão, [...] civilizar as relações humanas sobre o nosso planeta". Desse modo, é imprescindível desenvolver no cotidiano da sala de aula a relação dos alunos com a poesia, fugindo, das abordagens pragmáticas e de um ensino apenas baseado na memorização.

Esses primeiros pressupostos indicam caminhos que podem ser utilizados para o tratamento dos conteúdos geográficos, originando-sedo diálogo da geografia com a literatura. Como uma forma de analisar como essas questões podem ser desenvolvidas no ensino de Geografia, a temática referente a desvalorização dos rios urbanos foi escolhida para ser abordada com alunos do ensino médio de escolas do município de São Gonçalo - RJ.

A poluição dos rios urbanos é um assunto que aparece no currículo de geografia associado ao tópico da Hidrosfera. É uma temática relevante para o aluno analisar como os impactos ambientais presente no espaço urbano podem influenciar diretamente na sua vida. Os rios urbanos brasileiros são invisíveis para grande parte da população, uma vez que estão em estado de grande degradação ambiental o que o tornam um elemento subalternizado na paisagem urbana. É sabido que o acelerado processo de urbanização brasileira acarretou no grave comprometimento

ParaOnde!?, Porto Alegre, v.12 n.2, p.115-123, 2019.http://seer.ufrgs.br/paraonde Edição Especial - III Colóquio de Pesquisadores em Geografia Física Ensino de Geografia 
ambiental dos rios que atravessam o espaço urbano. Como afirma Nascimento \& Sacramento (2015),o rápido crescimento das cidades, associado à falta de planejamento urbano,tornou o riouma espécie de obstáculo a ser transposto, a fim de que o "desenvolvimento" das cidades pudesse ocorrer sem entraves.

As primeiras cidades surgiram ao redor de grandes rios, os quais eram considerados fontes importantes para o abastecimento de água e alimentos para as pessoas, e claro, eram também uma valiosa fonte de lazer, pois as águas ainda eram apropriadas para o banho. A água dos rios supria a necessidade da água para consumo, higiene e desenvolvimento das atividades agrícolas e artesanais, como também a sua presença junto às aglomerações urbanas favorecia as comunicações e o comércio entre as pessoas. Contudo, devido ao processo de urbanização, os rios em grande parte estão ocultos na paisagem urbana. Outro fator, como a pobreza urbana, é um elemento importante para compreender o processo de degradação ambiental das cidades, uma vez que, como afirma Souza (2013, p.84), "vários problemas ambientais, que irão causar tragédias sociais (como desmoronamentos e deslizamentos em encostas, enchentes e poluição atmosférica), têm origem em problemas sociais ou são, pelo menos, agravados por eles. "

Com o processo de intensa urbanização, a ação humana acabou trazendo grandes danos aos recursos hídricos como o assoreamento dos cursos d’água; ocupações desastrosas em mananciais que deviam ser preservados, a fim de que se mantivessem a saúde dos nossos rios. Outro grave problema foi a instalação de indústrias poluidoras muito próximas aos corpos hídricos, o que quase sempre resultou em despejo proibido de resíduos industriais, contribuindo para a morte dos rios. Além disso, ausência da atuação do poder público acabou transformando esses rios em locais de despejos de lixo e esgoto por parte da população. Esses fatos acabam explicando o porquê de nossos alunos, por exemplo, chamarem os rios urbanos "valões". Desse modo, o aumento populacional nas grandes metrópoles acarretou na ocupação de áreas de riscos, como nas margens dos rios, por moradias subnormais de uma população socialmente vulnerável.As áreas ambientalmente frágeis [...] são as que "sobram" para a moradia de grande parte da população. As consequências são muitas: poluição dos recursos hídricos e dos mananciais, banalização de mortes por desmoronamentos, enchentes, epidemias, etc. (MARICATO, 1999, p.17).

Desse modo, essas proposições devem ser trabalhadas com os alunos, a fim de compreender a relevância dos rios nas nossas vidas, bem como, os impactos ambientais sofridos pelos rios no contexto urbano e, por conseguinte, reflitam a importância de desenvolver uma consciência ambiental que analise criticamente as questões que envolvam a dominação da natureza pelo homem.

As atividades didáticas foram realizadas no CIEP (Centro Integrados de Educação Pública) 439 - Luiz Gonzaga Junior, localizado no Luiz Caçador, bairro periférico do município de São Gonçalo - RJ e no Instituto de Educação Clélia Nanci, localizado no bairro Brasilândia do mesmo município. As atividades foram feitas com alunos do ensino médio de ambas as escolas. Cerca de setenta discentes participaram das oficinas que foram desenvolvidas comomaneirade trabalhar a temática dos rios urbanos por meio da articulação entre dois campos do conhecimento: a geografia e a literatura.

ParaOnde!?, Porto Alegre, v.12 n.2, p.115-123, 2019.http://seer.ufrgs.br/paraonde Edição Especial - III Colóquio de Pesquisadores em Geografia Física Ensino de Geografia 
Dentro do contexto escolar, a oficina é uma prática pedagógica importante para haver o desenvolvimento de uma aprendizagem aberta e dinâmica que atue no sentido de promover uma maior troca de experiências entre os sujeitos que compõem o universo escolar. Assim, o estudo de um tema por meio das oficinas pedagógicas pode trazer para a escola práticas de ensino diversificadas que auxiliem na construção de uma abordagem reflexiva sobre as problemáticas abordadas.

Desta forma, compreende-se as oficinas como um espaço de diálogo e vivências, pois tem como princípio a construção coletiva do conhecimento. Busca-se, então, a partir das oficinas, superar a separação que há entre a teoria e a prática ao articular o conhecimento construído em sala de aula com a vida dos alunos. Assim, a oficina pode ser compreendida enquanto um caminho, isto é, um processo de construção para abordagem de um determinado conteúdo com a utilização de uma metodologia adequada. Desse modo, as oficinas no ensino da Geografia são meios para promover um melhor aprendizado pelos alunos. Partindo das atividades propostas, professores e alunos podem desenvolver experiências coletivas com o intuito de compreender os conceitos e conteúdos de forma mais dinâmica e interativa. Sobre a importância de desenvolver com os alunos novas atividades para pensar a produção do conhecimento, Sacramento (2017, p.4) defende queas atividades colaboram na formação e compressão dos "conceitos ou os fenômenos que trabalhamos em sala de aula,porque essas atividades precisam estar voltadas para o desenvolvimento mental dos alunos que são orientados por meio dos símbolos e dos instrumentos que se materializam em forma de conteúdo".

Desse modo, as oficinas podem ser compreendidas como um caminho, um meio de facilitar o processo de ensino-aprendizagem, utilizando-se de metodologias diversificadas como objetivo de construir alternativas,para que não haja apenas uma simples transmissão dos conteúdos geográficos. Busca-se então promover a participação coletiva entre os alunos, ampliar a capacidade de observaçãoe questionamento dos mesmos diante dos movimentos diversos da sociedade.

O tema "A desvalorização dos rios no contexto urbano" foi escolhido, para ser trabalhado nas escolas já referidas. Entre os procedimentos metodológicos realizados inicialmente nas oficinas, pode-seelencar um debate prévio com os alunos sobre a formação da hidrosfera com objetivo deincitar no alunado a compreensão da dinâmica dos recursos hídricos e que possamentender como se apropriam desse recurso. Como ressalta, Nascimento \& Sacramento (2015), ao abordar essas temáticas em sala de aula, é necessário utilizar também a escala do local, isto é, "trabalhar as multiescalaridades, pois o conteúdo sobre os rios urbanos precisa de uma leitura da sua paisagem, para que os estudantes tenham ciência do seu papel como cidadão para prover a saúde daquele corpo hídrico". Desse modo, a paisagem ao redor da escola serviu como ponto de partida, para que os alunos pudessem colocar seus primeiros questionamentos sobre as temáticas abordadas.

Esses primeiros tópicos foram trabalhados de forma breve com os alunos com o intuito fazer uma revisão sobre os principais conceitos e temas referentes à hidrologia. Entre os instrumentos utilizados nesse primeiro momento estão textos, mapas, gráficos e imagens. Por fim,a poluição das águas continentais, temática principal da oficina,foi abordada com os discentes, a partir da leitura e análise de três

ParaOnde!?, Porto Alegre, v.12 n.2, p.115-123, 2019.http://seer.ufrgs.br/paraonde Edição Especial - III Colóquio de Pesquisadores em Geografia Física Ensino de Geografia 
poemas: "Paisagem do Capibaribe" do poeta João Cabral de Melo Neto; "O maior trem do mundo" (1984) e "Lira Itabirana" (1984) do poeta Carlos Drummond de Andrade.

O primeiro poema utilizado na oficina -“Cão sem plumas" - foi escrito pelo poeta pernambucano João Cabral de Melo Neto. Esse aborda a questão da poluição do Rio Capibaribe que nasce no Agreste atravessa a Zona da Mata Norte e a região Metropolitana do Recife. Contudo, tal poema pode ser utilizado como um meio de reflexão sobre a situação da maioria dos nossos rios urbanos, já queo modelo capitalista de pensar a produção do espaço reproduz impactos ambientais e sociais com características bem similares em diferentes lugares.

Na visão de Feitosa; Lima (2013, p.58), no poema "Cão Sem Plumas",o rio Capibaribe não é descrito de imediato por uma representação direta, mas sim por meio de analogias. "Antes de visualizarmos o rio, somos tomados pelos valores atribuídos a ele e as sensações que provoca, tais como o desprezo, a falta de importância que reside no fato de um cachorro passar por uma rua, ou uma espada cortar uma mera fruta". O eu-líriconão denuncia apenas o estado de degradação do rio Capibaribe, mas também a situação de exclusão da população ribeirinha à margem da sociedade. O poema expõe a miserável vida dessa população socialmente vulnerável que sem condições de morar num lugar seguro e digno precisa se estabelecer nas margens dos rios levando uma vida insalubre, assim como são as águas daquele rio.

O poema constrói uma íntima articulação entre os elementos naturais que compõem a cidade como o rio, o lodo dos mangues, com as condições sociais e econômicas precárias dos moradores que habitam às margens do rio. Não existe uma diferenciação entre homem/rio/lama, os aspectos humanos e físicos estão interligados por meio destas construções metafóricas, nas quais o rio e o homem são igualmente "cães sem plumas". Assim, a interação do homem com o meio evidencia como as condições sociais são substancialmente deterioradas por conta da degradação da natureza no espaço urbano.O eu-líricoinusitadamente associa o rio a um cachorro, já queo formato da língua e do ventre de um cão é liso e comprido, lembrando a fisionomia do Capibaribe.

O rio é comparado a um cão sem plumas devido à ausência de vida, de cores e fertilidade, visto queo rio "nada sabia da chuva azul, da fonte cor-de-rosa, da água do copo" só conhece a sujeira, o abandono e a pobreza. Todos esses aspectos não remetem apenas para a situação do rio, mas igualmente retrata a vida do homem urbano que convive passivamente com o abandono do rio sem que haja nenhuma indignação por essa situação. Esse fato evidencia o conformismo e a pobreza tanto física,quanto moral dos sujeitos que não enxergam o rio como um elemento relevante capaz de produzir uma melhor qualidade de vida no espaço urbano se fossem bem cuidados.

Outros dois poemas escritos por Carlos Drummond: "O maior trem do mundo" e Lira Itabirana" também utilizados nas oficinas, algumas temáticas estão muito bem colocadas nos poemas e foram analisadas pelos alunos: a questão da relação do eu-lírico com o espaço vivido que se desdobra, a partir do vínculo com a natureza existente no lugar onde vive, porém essa natureza acaba sendo sucumbida pela prática predatória da mineração Sabe-se que além dos processos de degradação

ParaOnde!?, Porto Alegre, v.12 n.2, p.115-123, 2019.http://seer.ufrgs.br/paraonde Edição Especial - III Colóquio de Pesquisadores em Geografia Física Ensino de Geografia 
que ocorrem no local da extração dos minérios, os rejeitos produzidos por essa atividade podem chegar a diversos rios e destruir grande parte da flora e fauna de vários lugares.

Os poemas trazem uma crítica aos aspectos sociais, econômicos e ambientais que orbitam em torno da prática de uma mineração predatória. $O$ eu lírico fala sobre o trem que leva embora para outros países não apenas os minérios extraídos de sua terra natal, pois junto a eles também vão as suas lembranças e memórias afetivas aos poucos destruídas como ocorre com seu lugar de vivência.

Como ocorreu no caso da tragédia do rio Doce e seus afluentes no qual ecossistemas de vários municípios foram afetados. Num tom quase profético, já em 1984, Drummond evidenciava como as questões ambientais eram tratadas pela grande empresa de mineração Vale, enfatizando a exploração de forma devastadora da natureza pela mesma. Durante a leitura e reflexão do poema, é importante alertar os alunos, a fim de perceberem a responsabilidade das grandes empresas de mineração do Brasil e do mundo nesses acontecimentos, identificando como elas se apropriam da natureza e qual é tipo de relação que deviam estabelecer não só com o meio ambiente, como também com a população local, a fim de que tragédias ambientais desse gênero não ocorressem mais no país.

Por meio das problemáticas levantadas, o professor pode abordar vários conceitos e temas geográficos através do trabalho com o poema em sala de aula. $\mathrm{A}$ compreensão de um poema não constitui um processo fechado, pois, assim como ele faz parte da subjetividade de quem o criou, a sua compreensão também contará com o processo de imaginação e subjetividade de quem o lê. Ao gerar diversas interpretações, o ato de lê-lo também contribui para uma melhora na prática de leitura e escrita dos alunos, como também amplia a capacidade de compreensão sobre o tema trabalhado.

De acordo com Sacramento (2017, p.02), "as atividades didáticas devem possibilitar que os estudantes aprendam sobre um determinado tema, conceito e conteúdo para que saibam ler e interpretar sobre aquilo que estão a sua volta ou sobre aquilo que leem ou veem em outros ambientes." Desse modo, as atividades desenvolvidas com os alunos nas oficinas a partir da temática da desvalorização dos rios no contexto urbano tinham como objetivo compreender qual o grau de entendimento que os discentes já possuíam sobre as temáticas que estavam sendo em abordadas. Por conseguinte, a leitura dos poemas pelos alunos deve trazer para o debate as questões socioeconômicas e políticas relacionadas diretamente ao tema.

Assim, os alunos através de suas falas evidenciavam o grau de compreensão que tinham sobre a temática e apontavam o papel de cada sujeito, seja esse um cidadão comum, como também, o papel dos políticos de refletir sobre as medidas de curto, médio e longo prazo capazes de solucionar ou minimizar a degradação ambiental presente nas cidades brasileiras, como a poluição dos rios urbanos.

Como argumenta Sacramento (2012, p.108), "as diferentes linguagens têm como característica principal o texto escrito, sem o formalismo acadêmico ou mesmo o apuro didático de uma ferramenta formal de ensino, como forma de expressar um pensamento, uma descrição de uma paisagem ou sentimento. "Desse modo, a

ParaOnde!?, Porto Alegre, v.12 n.2, p.115-123, 2019.http://seer.ufrgs.br/paraonde Edição Especial - III Colóquio de Pesquisadores em Geografia Física Ensino de Geografia 
utilização dos poemas em sala de aula conseguiu despertar nos alunos um maior interesse pelo tema que estava sendo abordado, pois eles tiveram acesso a uma nova fonte de leitura, os poemas, que apresentam uma linguagem diferente do livro didático.

Esse comumente possui uma linguagem objetiva e rigorosa diferentemente do poema que abarca um discurso mais livre e subjetivo no seu texto. Foi um momento interessante, porque vários alunos disseram previamente que não sabiam como a literatura podia estar presente na aula de geografia e através da oficina puderam compreender que essa articulação entre esses dois ramos do conhecimento é de fato possível. A maior parte dos alunos nunca havia lido os poemas que foram utilizados nas oficinas, como também tinham pouco conhecimento sobre os poetas em questão. Assim, a partir das atividades os alunos puderam desenvolver novas reflexões sobre os temas abordados, conhecer poemas e, por conseguinte, autores importantes da literatura brasileira.

\section{Considerações finais}

Desenvolver atividades didáticas a partir do diálogo da geografia com a literatura nas oficinas traz para o ensino dos conteúdos geográficos a possibilidade de desenvolver uma aprendizagem que busque significados para os sujeitos envolvidos nesse processo, que valorize também a experiência prévia do aluno. Com a leitura e interpretação dos poemas, os alunos podem analisar as problemáticas presentes na realidade a partir de outras dimensões da formação humana como a emocional e a social, e não apenas por meio da racionalidade presente na linguagem científica dos livros didáticos, por exemplo.

Desse modo, os alunos podem através de diferentes linguagens construir um pensamento crítico e aprender a debater sobre questões relevantes que estão presentes no seu cotidiano e, com isso, se perguntarem por que tais coisas se apresentam de uma forma e não de outra. Como por exemplo, analisar o porquê do rio presente no seu bairro tem determinadas características em detrimento de outras que estão presentes em outros rios. Por que um rio é poluído outro não? São indagações que os alunos devem fazer para tomar consciência das problemáticas que dizem respeito a essa temática.

Com o término da oficina, os alunos já conseguiam perceber a relevância do diálogo entre esses dois saberes. Para a maior parte dos alunos, era a primeira vez que eles estavam entrando em contato com os autores e poemas utilizados nas oficinas, embora fosse alunos do ensino médio. Desse modo, as atividades demonstraram a importância de trabalhar com diferentes linguagens no ensino da geografia, seja por meio da música, jogo, charge, como também, com a literatura.

\section{Referências}

ALVES, José. Caminhos da abordagem do poema em sala de aula.Revista Graphos. João Pessoa, v. 10, n. 1, p. 19-33, 2008.

ParaOnde!?, Porto Alegre, v.12 n.2, p.115-123, 2019.http://seer.ufrgs.br/paraonde Edição Especial - III Colóquio de Pesquisadores em Geografia Física Ensino de Geografia 
ALVES, José. Contribuição da Estilística para o ensino da poesia. Via Atlântica, São Paulo, n. 28, p.143-159, dez/2015.

CALLAI, Helena Copetti. Temas e conteúdos no ensino de geografia. In: Currículos - Política Públicas e Ensino de Geografia. 1ed. Goiânia: Ed. da PUC, Goiás, 2015, v.1, pp.213-230.

CAVALCANTI, Lana de Souza. O ensino de Geografia na escola. São Paulo: Papirus, 2012.

FEITOSA, Márcia Manir Miguel; LIMA, Renata Ribeiro.A paisagem cultural em João Cabral de Melo Neto: As vivências do Capibaribe. In:Linha d’Água, n. 26 (1), p. 51 66, 2013.

MARANDOLA. JR; OLIVEIRA. Lívia de;Geograficidade e espacialidade na literatura. Rio Claro, v. 34, n. 3, p. 487-508, set. /dez. 2009.

MARICATO, Erminia. A terra é um nó, na sociedade brasileira...também nas cidades.Cultura Vozes, Petrópolis - Ed. Vozes, v.93, no 6, p.7-22, 1999.

NASCIMENTO, Daiana; SACRAMENTO, Ana Claudia;A formação do conceito de paisagem a partir da psicologia histórico-cultural na construção didática da atividade sobre o Rio Alcântara - SG-RJ. In:Revista Interface, Edição nº 09, junho de 2015. p. 7- 25.

SACRAMENTO, Ana Claudia Ramos. Diferentes linguagens na Educação Geográfica da cidade do Rio de Janeiro.IN: Revista Continentes (UFRRJ), ano 1, n.1, p. 97-118, 2012.

SACRAMENTO, Ana Claudia Ramos. Pensar a cidade de São Gonçalo por meio de atividades didáticas. In: XVI EGAL 2017, 2017, La Paz. XVI Encontro de Geógrafos de América Latina (EGAL 2017), Anais2017. v. 1. p. 1-13.

SOUZA, Marcelo Lopes de. ABC do desenvolvimento urbano. Rio de Janeiro: Bertrand Brasil, 2013. 